\begin{tabular}{|c|c|c|c|}
\hline 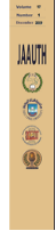 & 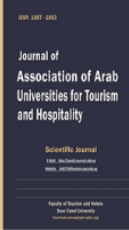 & 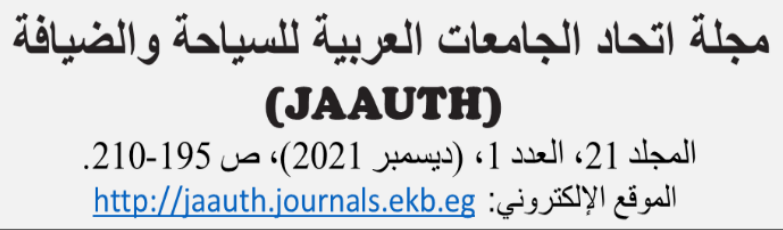 & 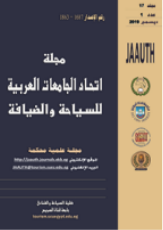 \\
\hline
\end{tabular}

تقييم جودة خريجي التعليم الثانوي السياحي الفني المتقدم وارتباطها بمتطلبات العمل بشركات السياحة بإقليم الالتا

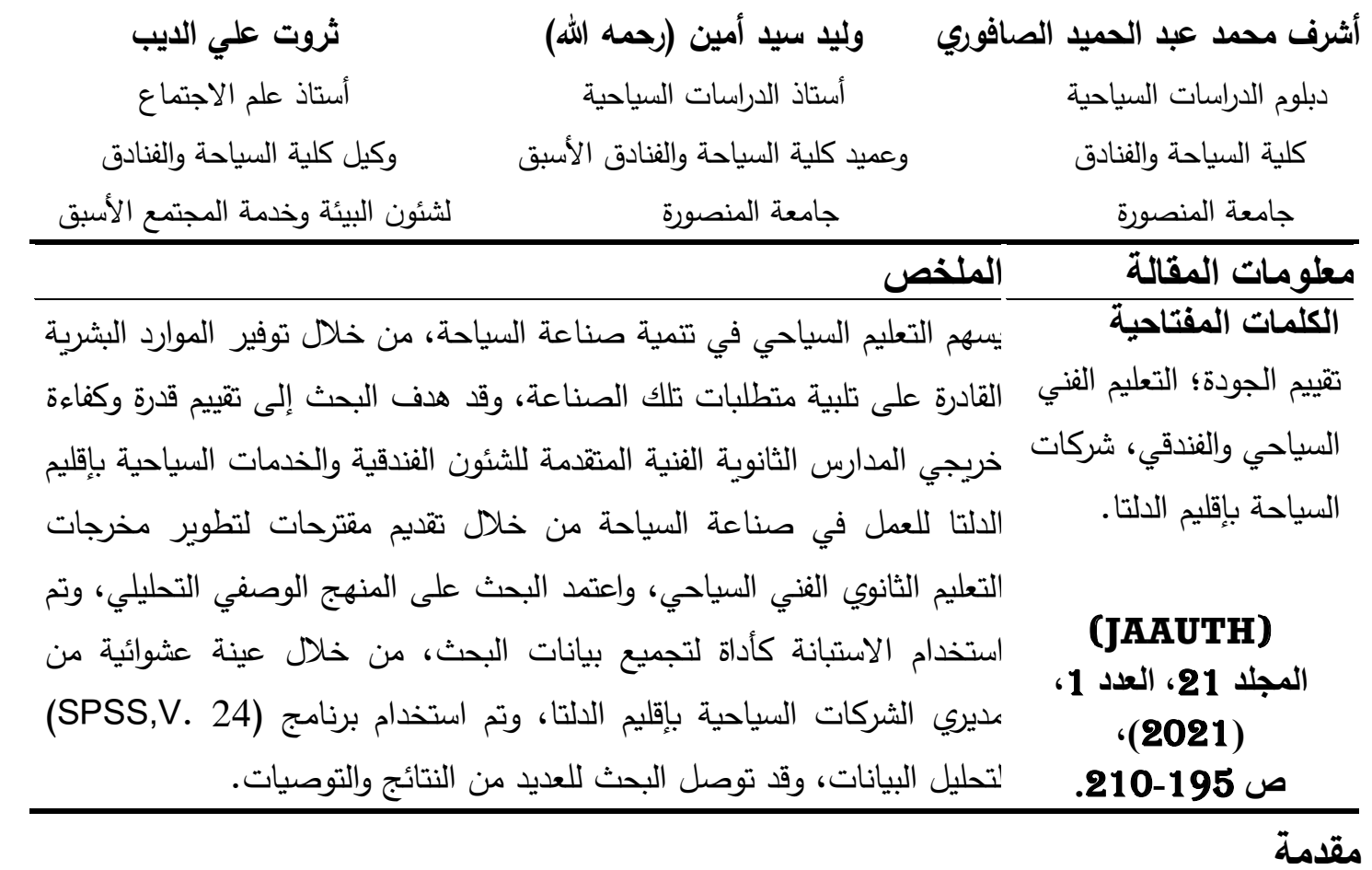

تعد السياحة المحرك الأساسي لاقتصاديات العديد من دول العالم المتقدم والنامي على حد سواء، كونها تمثل أهم الصناعات القادرة على تحقيق معدل نمو اقتصادي يفوق العديد من الصناعات الأخرى، ومن ثم شهدت الأنشطة السياحية تزايدًا وتطورًا في مجالات التخطيط والتسويق واستخدام التقنيات الحديثة، وصاحب ذلك تزايد الاهتمام

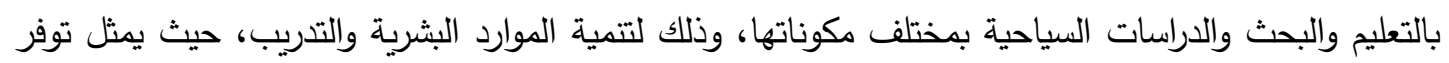
العنصر البشري الماهر والمؤهل لسوق العمل في مجالات السياحة أحد أهم التحديات التي تواجه هذه الصناعة. وللتعليم السياحي دور كبير في تطور صناعة السياحة عن طريق توفير الموارد البشرية القادرة على تلبية متطلبات تلك الصناعة، ويجد القائمون على صناعة السياحة وأصحاب الأعمال والمشروعات السياحية؛ إلا أن فئن المشكلة تكمن في عدم كفاية الموارد البشرية المؤهلة وانخفاض كفاءتها والتي لا تسنطيع أن تلبى الحاجة

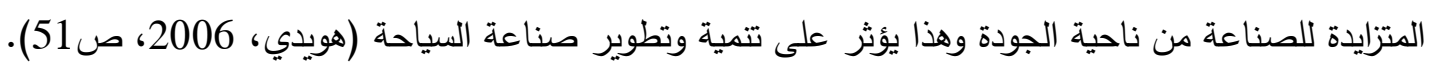

مشكلة البحث

تكمن مشكلة البحث في أن إقليم الدلتا لم يحصل بعد على نصيبه العادل من حركة السياحة الدولية الوافدة لجمهورية مصر العربية وأنه بحاجة للتطوير في العديد من المناحي ومنها الموارد البشرية العاملة في الشركات 
السياحية بذلك الإقليم والتي من الملاحظ أن نسبة ليست بالقليلة منها من غير المتخصصين في مجال السياحة،

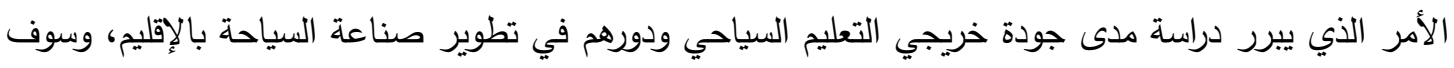

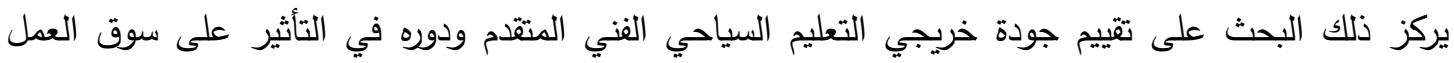
السياحي بالإقليم. - البرك.

\section{أهمية البحث}

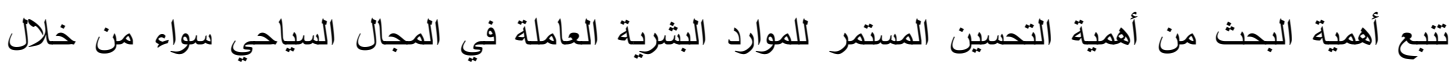

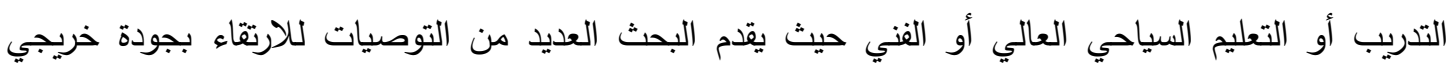

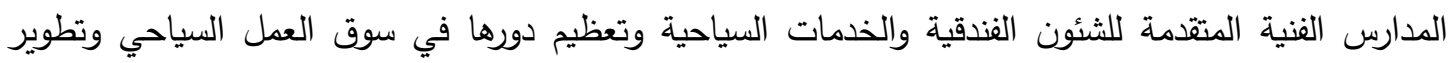
السياحة بإقليم الالتا.

أهداف البحث: تتمثل أهداف البحث في: 1. تقييم جودة خريجي المدارس الثانوية الفنية المتقدمة للشئون الفندقية والخدمات السياحية بإقليم الدلتا.

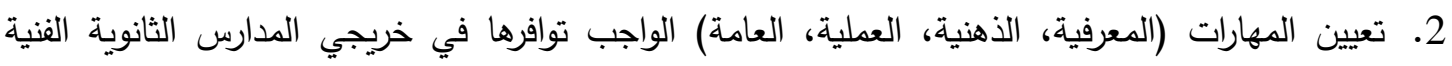
المتقدمة للشئون الفندقية والخدمات السياحية لتحقيق الجدارة المهنية.

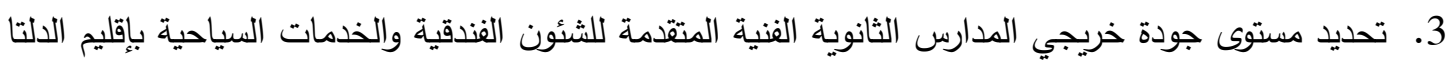
من وجهة نظر رجال الصناعة (مديري الشركات السياحية). 4. تقديم مقترحات لتطوير مخرجات التعليم الثانوي الفني السياحي لتعظيم إسهاماتها في سوق العياتيات العمل السياحي

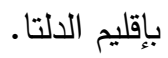

\section{فروض البحث}

تتمثل الفرضية الرئيسة للبحث في: توجد علاقة ارتباطية بين مستوى إلمام خريجي قسم الخدمات السياحية

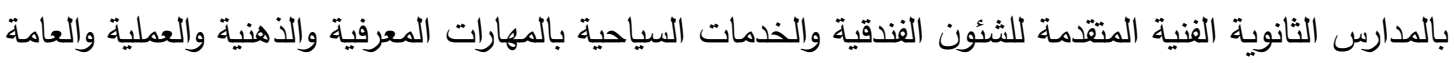
مع متطلبات سوق العمل السياحي بإقليم الدلتا.

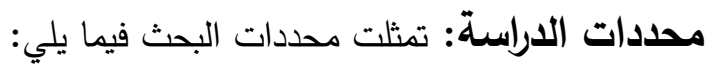

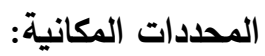

تم تطبيق البحث على خريجي المدارس الثانوية الفنية المتقدمة للشئون الفندقية والخدمات السياحية (قسم الخدمات السياحية "ثعبة السياحة الدينية والداخلية حاليًاً بمحافظات الدقهلية، والغربية، وكفر الشيخ، والعاملين بالشركات السياحية بذات المحافظات. 
الدراسة النظربـة

1- التعليم الفني السياحي في مصر النهر

1/1 تطور مدارس التعليم السياحي الفني في مصر فير

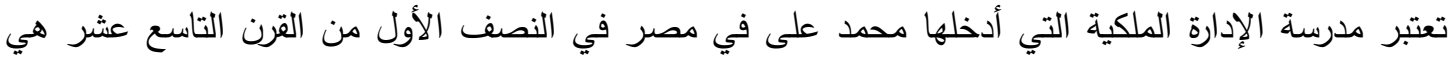

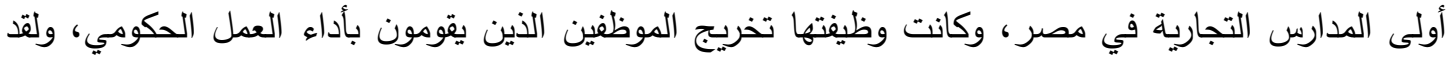

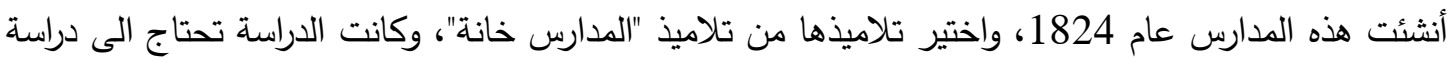

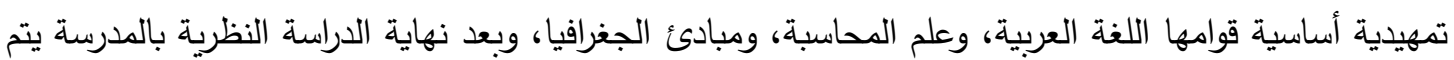

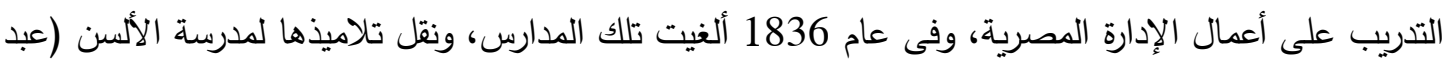

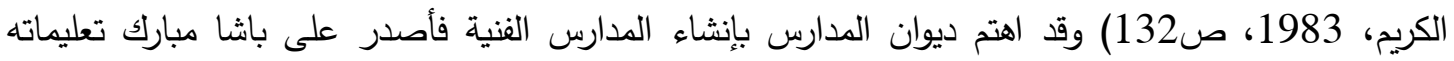

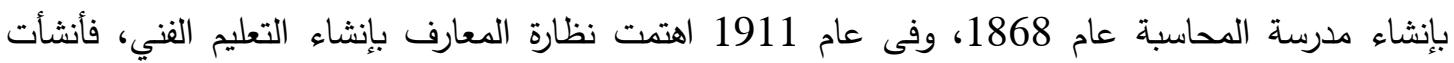

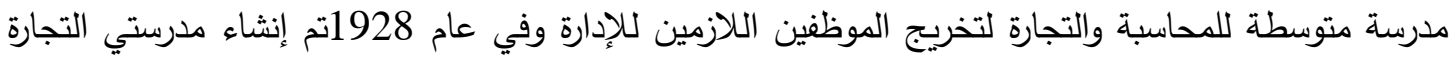

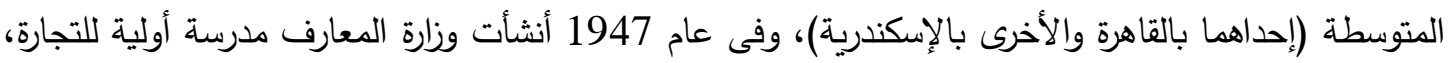
وقررت وزارة المعارف في عام1950 تقسيم التعليم الفني إلى (صناعي - زراعي - تجارى) (فؤاد، 1989 1950، ص88)، وفى عام 1951 صدر القانون رقم 142 لسنة 1951 في عهد طه حسين بتقسيم المدارس الثانوية إلى عامة وفنية (حجي، 1996، 1986، صام هذا وقد نشأت المدارس الفنية الفندقية (نظام ثلاث سنوات) في سبتمبر 1977 حيث تم إنشاء خمس مدارس تخصص شئون فندقية بالقرار الوزاري رقم (110) في 1977/6/27بشأن الفندقة (وزارة التربية والتعليم، 1977،

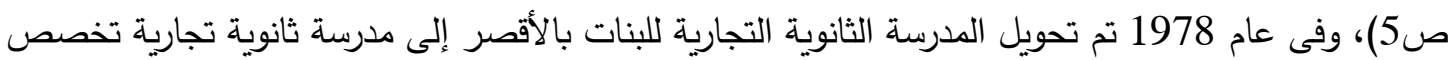

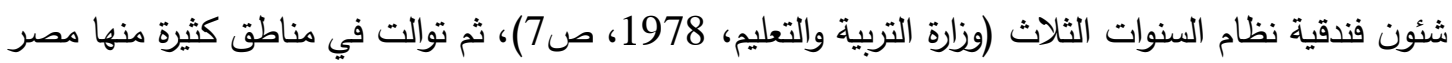

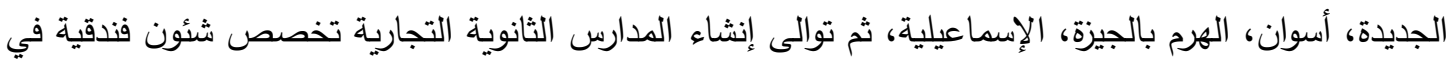
باقي المحافظات. وكانت نتيجة للاهتمام المتزايد بالتعليم الفندقي صدر القرار الوزاري رقم (93) بتاريخ التاريخ 1981/9/24 بإطلاق اسم الدرسة الثانوية الفندقية على المدارس الثانوية التجارية تخصص شئون فندقية (وزارة

$$
\text { التربية والتعليم، 1981، ص6/24) }
$$

هذا وقد صدر القرار الوزاري رقم (192) لسنة 1989بإنشاء الدارس الثانوية الفنية الدتقدمة للشئون الفندقية والخدمات السياحية نظام الخمس سنوات لإعداد فنيين في التخصصات الآتية (وزارة التربية والتعليم، 1989، التهاتية

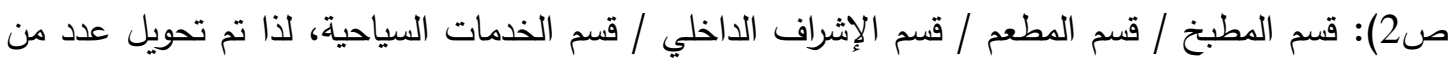
المدارس الثانوية الفنية الفندقية نظام السنوات الثلاث إلى الددارس الثانوية الفنية المتقدمة للشئون الفندقية والخدمات السياحية نظام السنوات الخمس مثل تحويل مدرسة كفر الثيخ الفندقية المتوسطة إلى المدرسة الفندقية

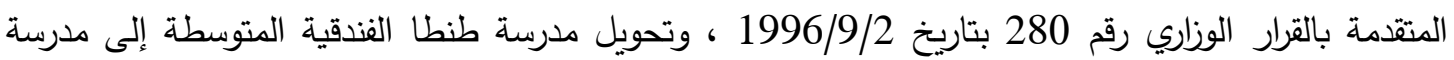


طنطا الفندقية المتقدمة بالقرار الوزاري رقم 456 بتاريخ 19/9/ 1999، ويركز هذا البحث على خريجي قسم

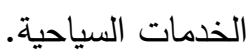

2/1 فلسفة التعليم الفني السياحي

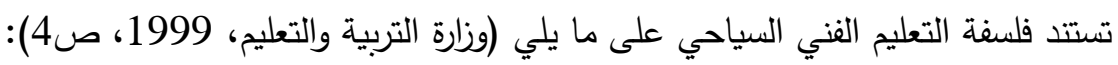

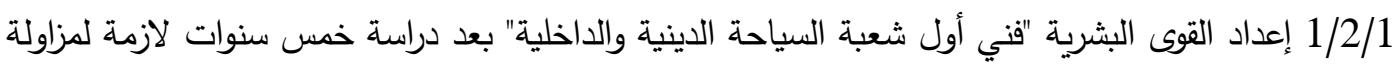

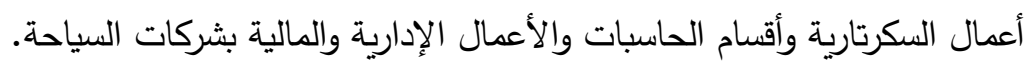

2/2/1 تزويد الطلاب بقسم السياحة الدينية والداخلية بقدر من الثقافتين العامة والمتخصصة والربط بينهما

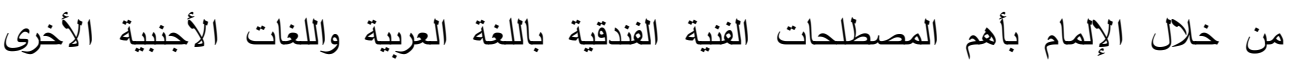

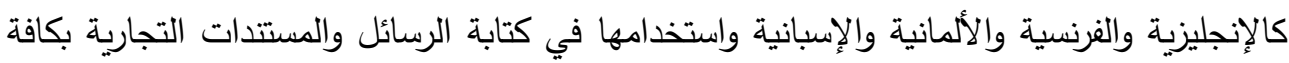
أشكالها وأنواعها من خلال التدريب على نماذج أعمال السكرتارية.

$$
\text { 3/2/1 توفير العمالة الماهرة لمواجهة احتياجات الشركات السياحية. }
$$

3/1 الأقسام التخصصية بالمدرسة الفنية المتقدمة للشئون الفندقية والخدمات السياحية

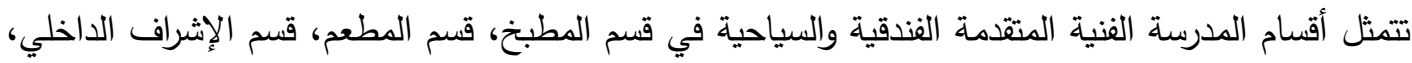

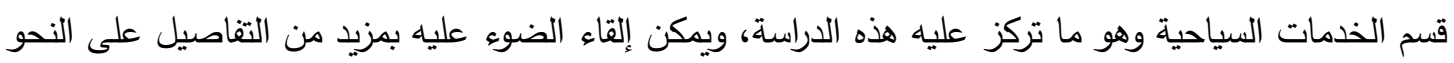

قسم الخدمات السياحية (شعبة السياحة الدينية والداخلية)، يلتحق الطالب بالصف الثالث تخصص شعبة

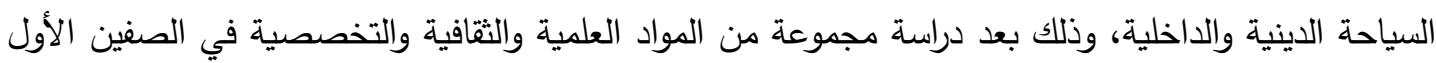

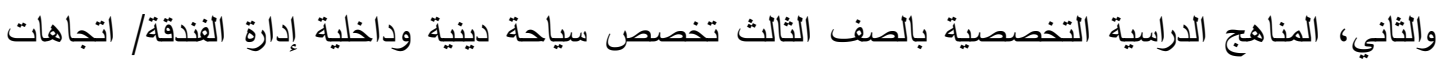

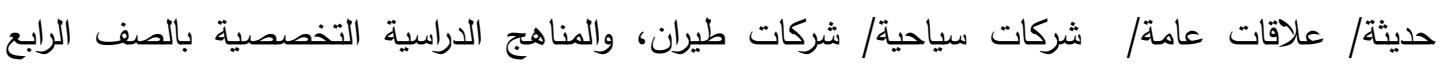

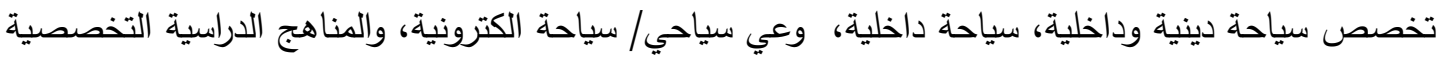

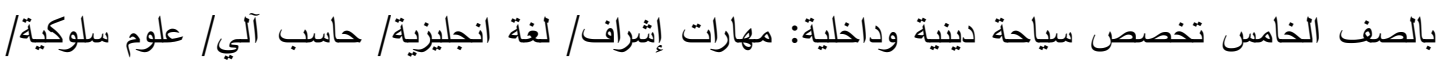
اتصال ومراسلات/ أنماط السياحة الحديثة/ لغة فرنسية/ سياحة دينية. (وزارة التربية والتعليم (2015)

\section{2 - 2 - 2 ادوة التعليم السياحي الفني 1/2}

إن مصطلح الجودة (Quality) مشتق من (Qualities) ويعني بها الثيء أو الثخص ودرجة صلاحه، وهي

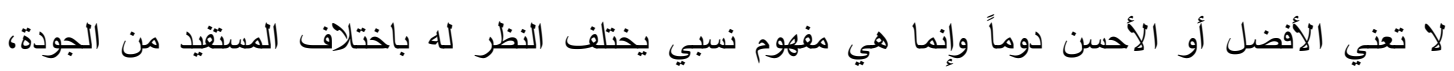

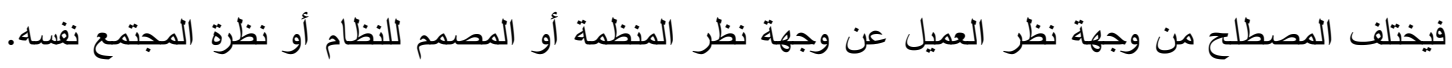

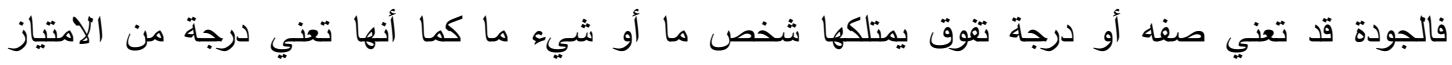

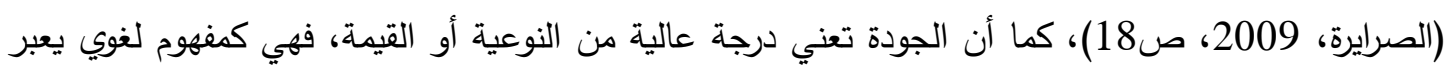


عن صفة ملازمة ومرتبطة بالموصوف الجيد، وتعني بثكل عام بعض الدرجات أو المؤشرات التي يمكن من

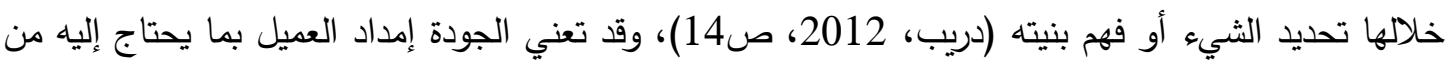

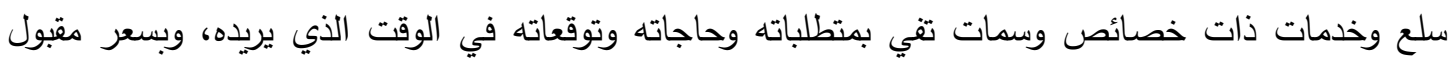

$$
\text { يلائمه (السامرائي، 2012، دات دات }
$$

\section{2/2 أهداف نظم إدارة الجودة في مؤسسات التعليم الفني السياحي}

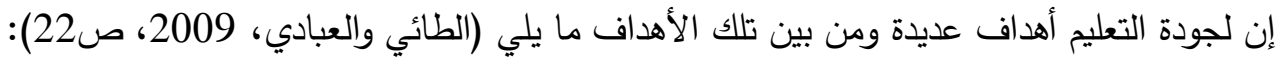
1/2/2 تطوير الأداء عن طريق تتمية روح العمل التعاوني الجماعي بهدف الاستفادة من كافة الطاقات ولاتيات بالمنثأة التعليمية.

2/2/2 ترسيخ مفاهيم الجودة الثاملة، والتي من أبرز مبادئها أداء العمل بطريقة صحيحة من أول مرة وفي

$$
\text { كل مرة). }
$$

3/2/2 تحقيق نقلة نوعية في العملية التعليمية تقوم على أساس التوثيق للبرامج والإجراءات والتفعيل للأنظمة

$$
\text { واللوائح والتوجيهات بمستويات الطلبة. }
$$

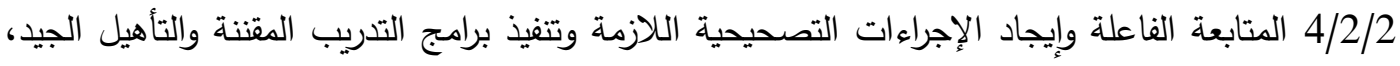

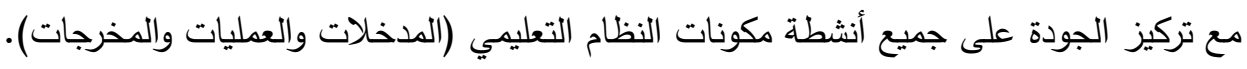

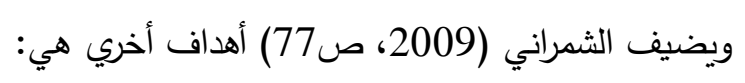

5/2/2 اتخاذ كافة الإجراءات الوقائية لتلافي الأخطاء قبل وقوعها ورفع درجة الثقة لدى العاملين والعمل على تحسين مستوى الجودة بصفة مستمرة.

6/2/2 الوقوف على المشكلات التعليمية في الواقع العملي، ودراسة هذه المشكلات وتحليلها بالأساليب

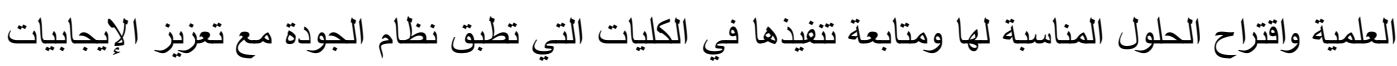

$$
\text { والعمل على تلافي السلبيات. }
$$

7/2/2 التواصل المستمر مع الجهات المستفيدة والمنظمات وسوق العمل لتحديث برامج الجودة وتطويرها بما يتقق مع النظام التعليمي.

\section{3/2 مواصفات جودة خريجي المدارس الفنية المتقدمة السياحية}

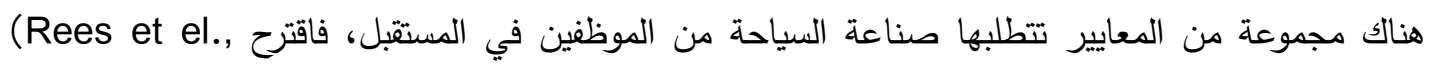

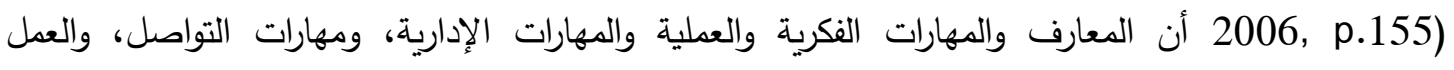

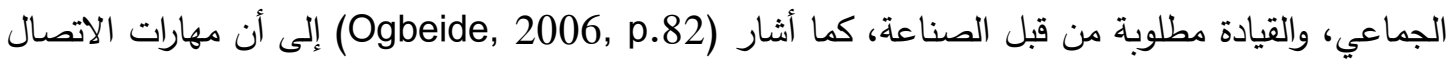

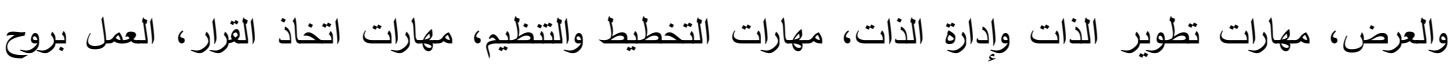

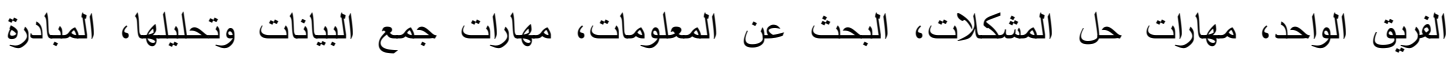

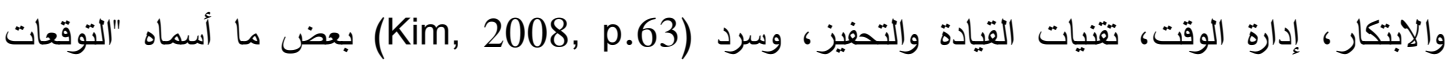


والمتطلبات المهنية" من الطلبة والصناعة وتم إدراج مهارات التواصل، استخدام مهارات المبادرة، مهارات العلاقات الإنسانية. المهارات التثغيلية، مهارات حل المشاكل، مهارات الإدارة الذاتية، مهارات اللغات المتعددة. كما ذكر (Jameson, 2008, p.16) أن مهارات التواصل، ومهارات المبادرة، ومهارات العلاقات الإنسانية،

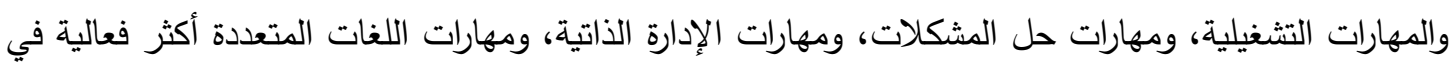
هذه الصناعة، وأكد (Chang, 2009, p.14) على الحاجة إلى المهارات المعرفية، والمهارات الثخصية، ومهارات التواصل، وتكنولوجيا المعلومات، ومهارات استخدام التكنولوجيا والأساليب الإحصائية الرياضية. هذا ويعد التعليم الفني السياحي بنظام الخمس سنوات هو مرحلة متقدمة في التعليم ويتمثل بالجهود والبرامج

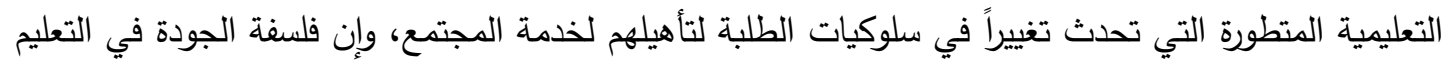

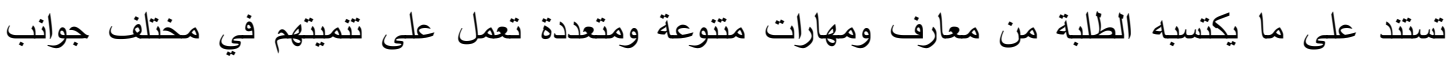

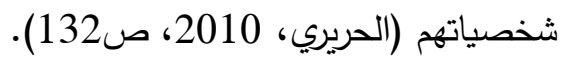

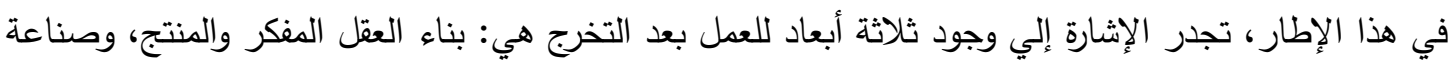

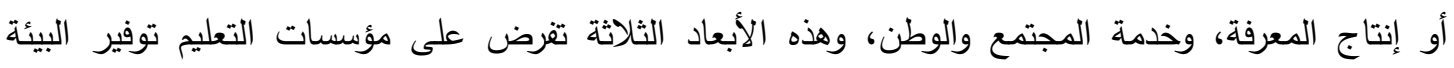

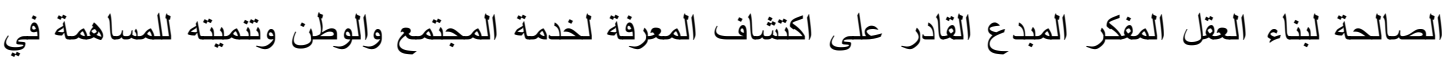

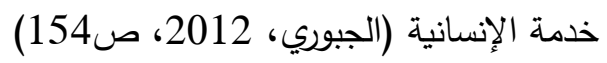

\section{منهجية البحث}

ارتكز البحث علي المنهج الوصفي التحليلي؛ وذلك بالاعتماد على المراجع العربية والأجنبية المتاحة فضلاً عن

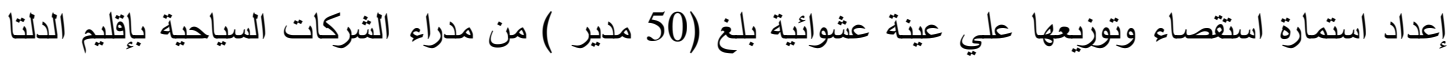

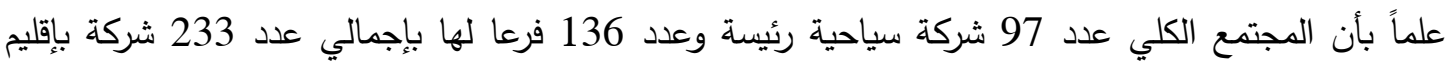
الالتا؛ وذلك لاستطلاع رأي مديري الثركات السياحية في مدى توافر المهارات المعرفية والذهنية والعملية والعامة لئية

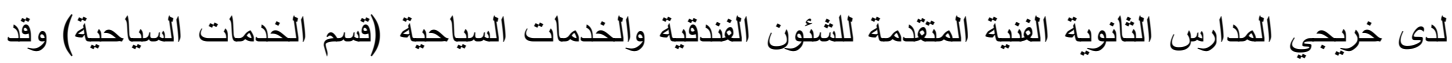

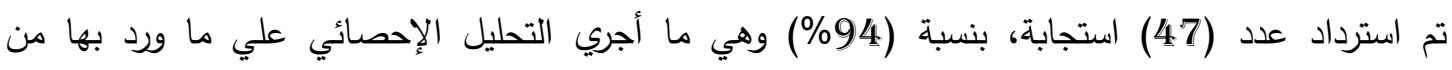

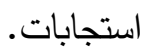

ثبات الاستبيان

جدول (1) معامل الثبات الفا كرونباخ لمحاور الاستبيان

\begin{tabular}{|c|c|c|c|c|}
\hline نسبة الثبات & معامل الثبات & عدد الفقرات & حجم العينة & المجتمع \\
\hline$\% 84$ & 0.840 & 28 & 47 & 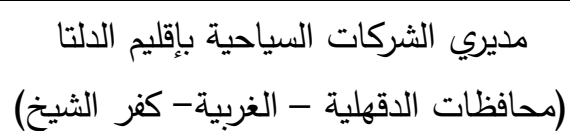 \\
\hline
\end{tabular}

يتضح من الجدول (1) أن قيمة معامل ألفا - كرونباخ لجميع محاور الاستبانة بلغت (0.840) بنسبة ثبات بلغت (84\%) وهي قيمة مقبولة وهذا يدل على التوافق بين فقرات الاستبيان. 


\section{الاحصاء الوصفي لاستجابات عينة الدراسة}

أولاً: البيانات الايموجرافية الأيفات

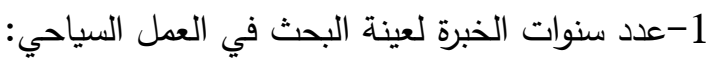

جدول (2) عدد سنوات الخبرة لعينة الدراسة

\begin{tabular}{|c|c|c|c|}
\hline$\%$ & التكرار & & \\
\hline 6.4 & 3 & اقل من 5 سنوات & \multirow{3}{*}{ عدد سنوات الخبرة في العمل السياحي } \\
\hline 6.4 & 3 & من5 إلى 10 سنوات & \\
\hline 87.2 & 41 & أكثر من 10 سنوات & \\
\hline
\end{tabular}

تشير بيانات الجدول رقم (2) أن عدد سنوات خبرة العمل في الشركات السياحية جاء في المرتبة الأولى ذاتى

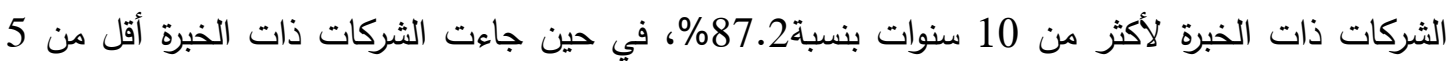

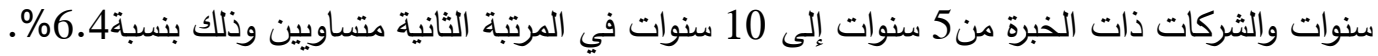
2- التواصل بين عينة البحث والمدارس الثانوية الفنية السياحية المتقدمة جدول (3) التواصل بين عينة البحث والددارس الثانوية الفنية السياحية المتقدمة

\begin{tabular}{|c|c|c|c|}
\hline$\%$ & 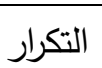 & & \\
\hline 2.1 & 1 & نعم & هل يوجد أي تواصل بينك وبين الددارس الثانوية \\
\hline 97.9 & 46 & $y$ & الفنية السياحية المتقدمة بمؤسستكم؟ \\
\hline
\end{tabular}

أوضح تحليل البيانات بالجدول رقم (3) أن عدم وجود تواصل بين الثركة وبين المدارس الثانوية الفنية

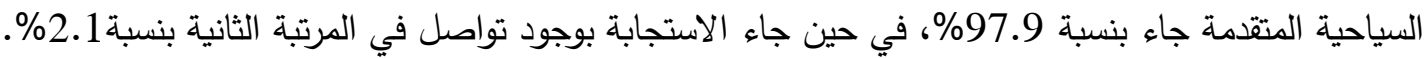
3- تفضل تدريب وتوظيف خريجي الدارس الثانوية الفنية السياحية المتقدمة بالمنثأة.

جدول (4) تدريب وتوظيف خرجي المدارس الثانوية الفنية السياحية المتقدمة

\begin{tabular}{|c|c|c|c|}
\hline$\%$ & التكرار & & \\
\hline 42.6 & 20 & نعم & \multirow{2}{*}{ الثانوية الفنية السياحية المتقدمة بالمنشأةّ؟ خديف } \\
\hline 57.4 & 27 & $\gamma$ & \\
\hline
\end{tabular}

تثير البيانات بجدول (4) إلى عدم تفضل الشركات السياحية تدريب وتوظيف خريجي المدارس الثانوية الفنية السياحية المتقدمة بنسبة57.4\%، في حين جاءت الاستجابة بتفضيل تدريب وتوظيف خريجي الدارس

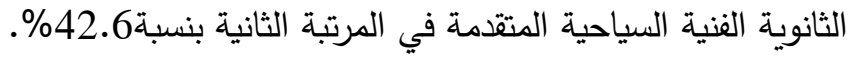
4- سبب معرفة شركات السياحة بوجود قسم للخدمات السياحية بالددارس الثانوية الفنية المتقدمة للشئون الفندقية والخدمات السياحية. 
جدول (5) معرفة شركات السياحة بوجود قسم للخدمات السياحية

\begin{tabular}{|c|c|c|c|}
\hline$\%$ & التكرار & & \\
\hline 80.9 & 38 & تدريب الطلاب & \multirow{4}{*}{ للخبب معرفة شركات السياحة بوجود قسم السياحية بالمدارس الثانوية الفنية } \\
\hline 6.4 & 3 & توظيف الخريجين & \\
\hline 10.6 & 5 & حضور ندوات ووش العمل & \\
\hline 2.1 & 1 & تقديم الاستشارات الفنية & \\
\hline
\end{tabular}

تبين النتائج بجدول (5) أن سبب معرفة شركات السياحة بوجود قسم للخدمات السياحية بالمدارس الثانوية الفنية المتقدمة للشئون الفندقية والخدمات السياحية: هو تدريب الطلاب في المرتبة الاولى بنسبة.80.9\%، وحضور الندوات وورش العمل في المرتبة الثانية بنسبة10.6\%، وتوظيف الخريجين في المرتبة الثالثة بنسبة 6.4\%، وتقديم الاستثارات الفنية في المرتبة الرابعة بنسبة 2.1\% وحتبة 5- مستوى المهارات والمعارف لدى خريجي المدارس الثانوية الفنية السياحية المتقدمة (قسم الخدمات السياحية). جدول (6) مستوي المهارات والمعارف لدي الخريجين

\begin{tabular}{|c|c|c|c|}
\hline$\%$ & التكرار & & \\
\hline 2.1 & 1 & نعم & \multirow{3}{*}{ 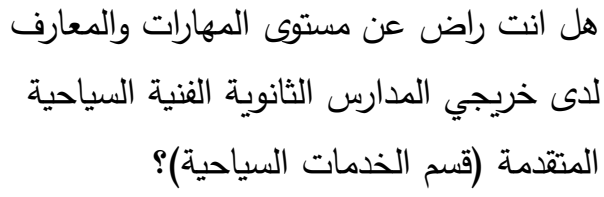 } \\
\hline 23.4 & 11 & إلى حد ما & \\
\hline 74.5 & 35 & $y$ & \\
\hline
\end{tabular}

وأوضحت النتائج بجدول (6) أن عدم الرضا لدي عينة الدراسة عن مستوى المهارات والمعارف لدى خريجي المدارس الثانوية الفنية السياحية المتقدمة في المرتبة الأولى بنسبة 74.5\%، في حين جاء الرضا إلى حد ما في المرتبة الثانية بنسبة 23.4\%، وجاءت الاستجابة بالرضا في المرتبة الثالثة بنسبة 2.1\% 6- تقييم مستوى إلمام خريجي المدارس الثانوية الفنية للشئون الفندقية والخدمات السياحية (قسم الخدمات السياحية) بمهارات المعرفة والفهم لمواكبة متطلبات سوق العمل.

جدول (7) تقييم مستوى إلمام خريجي المدارس الثانوية الفنية للشئون الفندقية والخدمات السياحية (قسم الخدمات السياحية) بمهارات المعرفة والفهم لمواكبة متطلبات سوق العمل

\begin{tabular}{|c|c|c|c|c|c|c|c|c|c|}
\hline \multirow{2}{*}{ الانحراف } & \multirow{2}{*}{ الحسوسط } & \multicolumn{4}{|c|}{ الاستجابة } & & \multirow{2}{*}{\multicolumn{2}{|c|}{ المهارات }} & \multirow[t]{2}{*}{ r } \\
\hline & & غير متوفرة & $\begin{array}{c}\text { غتوفيرة } \\
\text { (2) }\end{array}$ & $\begin{array}{l}\text { محايد } \\
\text { (3) }\end{array}$ & متوفرة & متوفرة & & & \\
\hline \multirow[t]{2}{*}{0.971} & \multirow[t]{2}{*}{2.72} & 4 & 17 & 15 & 10 & 1 & ك & \multirow{2}{*}{ 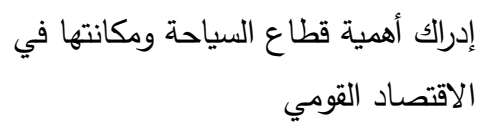 } & 1 \\
\hline & & 8.5 & 36.2 & 31.9 & 21.3 & 2.1 & $\%$ & & \\
\hline
\end{tabular}




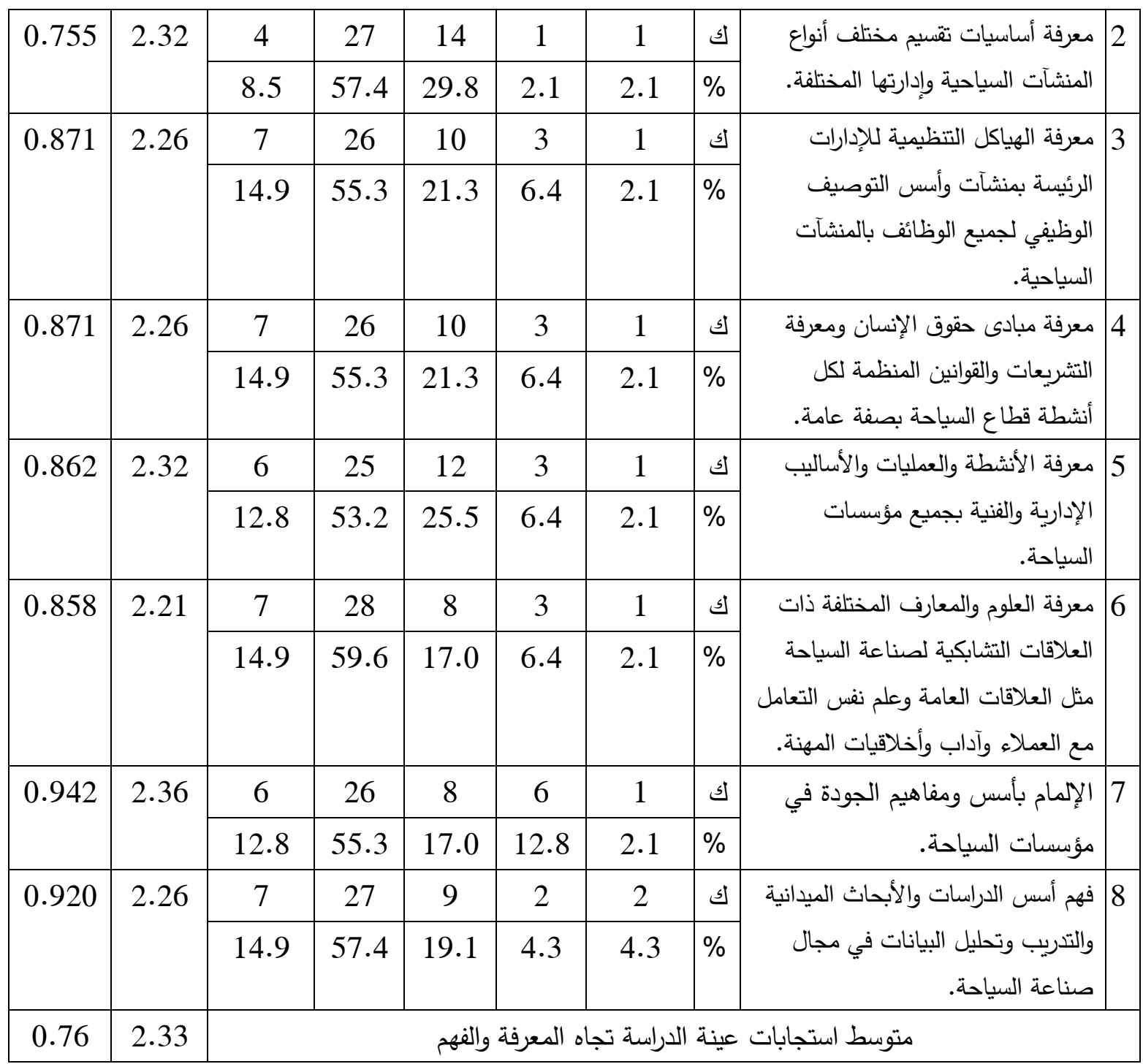

يتضح من جدول (7) وجهة نظر مديري الثركات السياحية حول تقييم مستوى إلمام خريجي الددارس

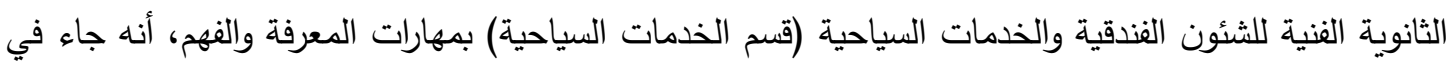

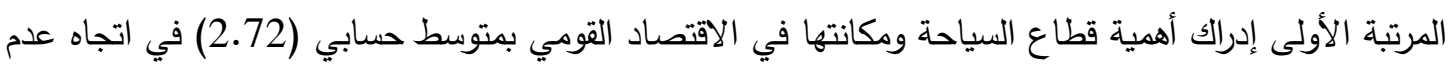

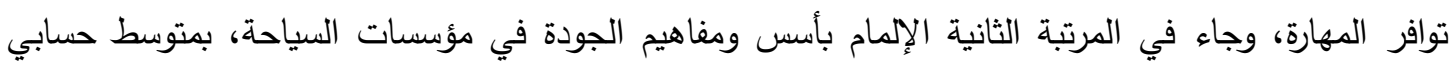

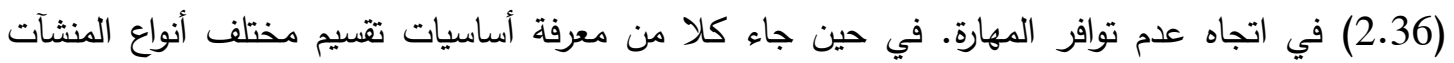

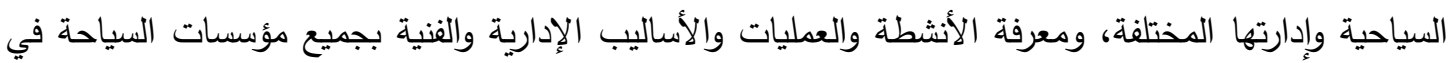
المرتبة الثالثة بمتوسط حسابي (2.32) في اتجاه عدم توافر المهارة. بينما اشترك كلا من معرفة الهياكل التتظيمية للإدارات الرئيسية بمنشآت وأسس التوصيف الوظيفي لجميع الوظائف بالمنشآت السياحية، ومعرفة

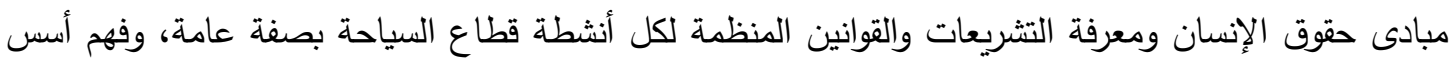

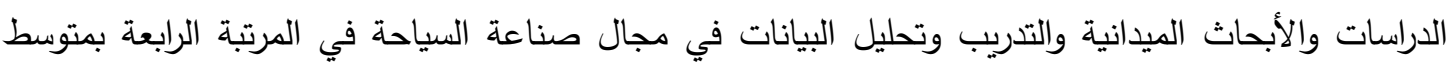




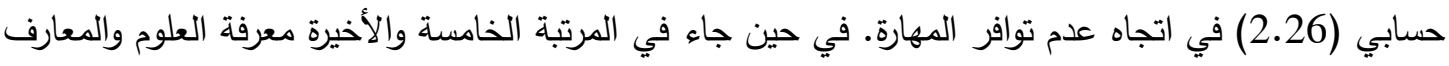

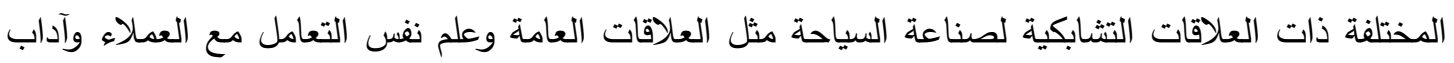

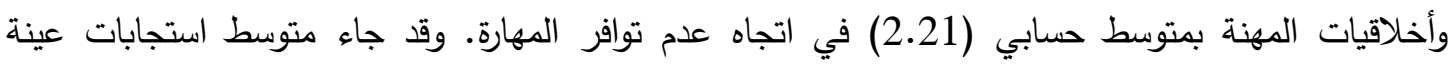
الدراسة تجاه المحور الاول المعرفة والفهم بمتوسط حسابي (2.33) في اتجاه عدم توافر المهارة. 7- تقييم ددي توافر المهارات الذهنية لدي خريجي الددارس الثانوية الفنية للشئون الفندقية والذذمات السياحية (قسم الخدمات السياحية) بالمهارات الذهنية لمواكبة متطلبات سوق العمل السياحي.

جدول (8) تقييم مدي توافر المهارات الذهنية لدي خريجي الددارس الثانوية الفنية للثئون الفندقية والخدمات السياحية (قسم الخدمات السياحية) بالمهارات الذهنية لمواكبة متطلبات سوق العمل السياحي

\begin{tabular}{|c|c|c|c|c|c|c|c|c|c|}
\hline \multirow{2}{*}{ المعياري } & \multirow{2}{*}{ المسابي } & \multicolumn{5}{|c|}{ الاستجابة } & \multirow{2}{*}{\multicolumn{2}{|c|}{ المهارات }} & \multirow[t]{2}{*}{ r } \\
\hline & & غير متفرة & غ غ غتوفرة & محايد & متوفرة & متوفرة & & & \\
\hline \multirow[t]{2}{*}{0.786} & \multirow[t]{2}{*}{2.23} & 6 & 28 & 9 & 4 & 0 & ك & \multirow{2}{*}{ التختلفة في قطاع صنائي لبيانات المنشأة } & \multirow[t]{2}{*}{1} \\
\hline & & 12.8 & 59.6 & 19.1 & 8.5 & 0.0 & $\%$ & & \\
\hline \multirow[t]{2}{*}{0.846} & \multirow[t]{2}{*}{2.26} & 6 & 28 & 9 & 3 & 1 & ك & \multirow{2}{*}{ مؤسسات السياحة وحاجة المجتمع } & \multirow[t]{2}{*}{2} \\
\hline & & 12.8 & 59.6 & 19.1 & 6.4 & 2.1 & $\%$ & & \\
\hline \multirow[t]{2}{*}{0.832} & \multirow[t]{2}{*}{2.30} & 6 & 26 & 10 & 5 & 0 & كs & \multirow{2}{*}{ العمل. القرارات وفقا لمتطلبات بيئة } & \multirow[t]{2}{*}{3} \\
\hline & & 12.8 & 55.3 & 21.3 & 10.6 & 0.0 & $\%$ & & \\
\hline \multirow[t]{2}{*}{0.826} & \multirow[t]{2}{*}{2.28} & 6 & 27 & 9 & 5 & 0 & s & \multirow{2}{*}{ 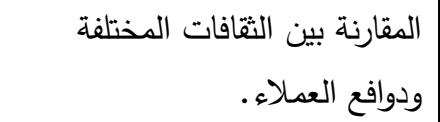 } & \multirow{2}{*}{4} \\
\hline & & 12.8 & 57.4 & 19.1 & 10.6 & 0.0 & $\%$ & & \\
\hline \multirow[t]{2}{*}{0.786} & \multirow[t]{2}{*}{2.23} & 6 & 28 & 9 & 4 & 0 & كs & \multirow{2}{*}{ للأطراف الممثلة لصناعة العلاقات المتثابكة } & \multirow{2}{*}{5} \\
\hline & & 12.8 & 59.6 & 19.1 & 8.5 & 0.0 & $\%$ & & \\
\hline 0.76 & 2.25 & \multicolumn{8}{|c|}{ متوسط استجابات عينة الدراسة تجاه المهارات الذهنية } \\
\hline
\end{tabular}

يتضح من الجدول (8) أنه جاء في المرتبة الأولى مهارة اتخاذ القرارات وفقًا لمتطلبات بيئة العمل بمتوسط

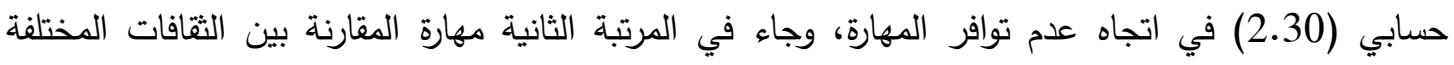

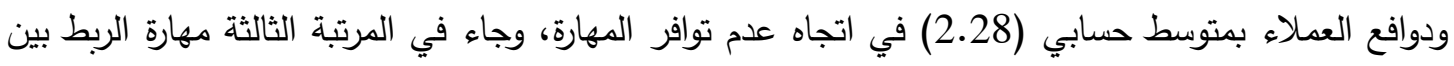

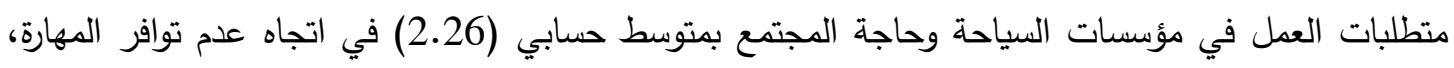

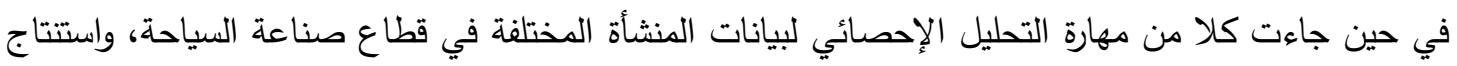
العلاقات المتثابكة للأطراف الممثلة لصناعة السياحة في المرتبة الرابعة بمتوسط حسابي (2.23) في اتجاه عدم توافر المهارة، وجاء متوسط استجابات عينة الدراسة تجاه محور المهارات الذهنية بمتوسط حسابي (2.25) في اتجاه عدم توافر المهارة. 
8- تقييم المهارات المهنية والعملية لدي خريجي قسم الخدمات السياحية بالمدارس الفنية المتقدمة للشئون الفندقية والخدمات السياحية.

جدول (9) تقييم مستوى إلمام خريجي المدارس الثانوية الفنية السياحية المتقدمة بالمهارات المهنية والعملية لمواكبة متطلبات سوق العمل السياحي

\begin{tabular}{|c|c|c|c|c|c|c|c|c|c|}
\hline \multirow{2}{*}{ |الانحراف } & \multirow{2}{*}{ |لمتوسط } & \multicolumn{5}{|c|}{ الاستجابة } & \multirow{2}{*}{\multicolumn{2}{|c|}{ المهارات }} & \multirow[t]{2}{*}{ r } \\
\hline & & غير متوفرة & غتوفرة & محايد & متوفرة & متوفزة & & & \\
\hline \multirow[t]{2}{*}{0.845} & \multirow[t]{2}{*}{2.36} & 6 & 23 & 13 & 5 & 0 & ك & \multirow{2}{*}{ والعمل في مختلف المهن } & \multirow[t]{2}{*}{1} \\
\hline & & 12.8 & 48.9 & 27.7 & 10.6 & 0.0 & $\%$ & & \\
\hline \multirow[t]{2}{*}{0.815} & \multirow[t]{2}{*}{2.34} & 6 & 23 & 14 & 4 & 0 & 5) & \multirow{2}{*}{ المارسة إجراءات السلامة } & \multirow[t]{2}{*}{2} \\
\hline & & 12.8 & 48.9 & 29.8 & 8.5 & 0.0 & $\%$ & & \\
\hline \multirow[t]{2}{*}{0.927} & \multirow[t]{2}{*}{2.43} & 6 & 23 & 10 & 8 & 0 & 5 & \multirow{2}{*}{ الجراء العمليات المحاسبية والمالية } & \multirow[t]{2}{*}{3} \\
\hline & & 12.8 & 48.9 & 21.3 & 17.0 & 0.0 & $\%$ & & \\
\hline \multirow[t]{2}{*}{0.583} & \multirow[t]{2}{*}{2.09} & 6 & 31 & 10 & 0 & 0 & ك) & \multirow{2}{*}{ فن فوظيف العلوم المرتبطة مثل علم } & \multirow[t]{2}{*}{4} \\
\hline & & 12.8 & 66.0 & 21.3 & 0.0 & 0.0 & $\%$ & & \\
\hline \multirow[t]{2}{*}{0.890} & \multirow[t]{2}{*}{2.23} & 7 & 28 & 7 & 4 & 1 & 5) & إعداد وتتظيم وإدارة أنشطة & \multirow[t]{2}{*}{5} \\
\hline & & 14.9 & 59.6 & 14.9 & 8.5 & 2.1 & $\%$ & أعمال الثركات السياحية. & \\
\hline 0.73 & 2.28 & \multicolumn{8}{|c|}{ متوسط استجابات عينة الدراسة تجاه المهارات المهنية والعملية } \\
\hline
\end{tabular}

يتضح من الجدول (9) انه جاء فى المرتبة الاولى مهارة إجراء العمليات المحاسبية والمالية المطبقة فى شركات السياحة بمتوسط حسابي (2.43) في اتجاه عدم توافر المهارة، وجاء فى المرتبة الثانية مهارة العمل فى مختلف الوظائف فى شركات السياحة بمتوسط حسابي (2.36) في اتجاه عدم توافر المهارة، وجاء فى المرتبة الثالثة مهارة ممارسة إجراءات السلامة المهنية والإسعافات الأولية اللازمة للعمل بشركات السياحة بمتوسط حسابي (2.34) في اتجاه عدم توافر المهارة، وجاء إعداد وتتظيم وإدارة أنشطة أعمال الثركات السياحية مستخدما التقنيات الحديثة فى المرتبة الرابعة بمتوسط حسابي (2.23) في اتجاه عدم توافر المهارة، أما المرتبة الخامسة والأخيرة فقد جاءت مهارة توظيف العلوم المرتبطة مثل علم نفس العملاء - البيئة- التشريعات السياحية لخدمة 
مجالات العمل فى الثركات السياحية بمتوسط حسابي (2.09) في اتجاه عدم توافر المهارة، وجاء متوسط

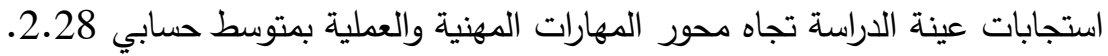
9- تقييم المهارات العامة لدى خريجي قسم الخدمات السياحية بالمدارس الثانوية الفنية المتقدمة للشئون الفندقية والخدمات السياحية

جدول (10) تقييم مستوى إلمام خريجي المدارس الثانوية الفنية السياحية المتقدمة بالمهارات العامة لمواكبة متطلبات سوق العمل السياحي

\begin{tabular}{|c|c|c|c|c|c|c|c|c|c|}
\hline \multirow{2}{*}{ الالحرراف } & \multirow{2}{*}{ الحسابي } & \multicolumn{4}{|c|}{ الاستجابة } & & \multirow{2}{*}{\multicolumn{2}{|c|}{ المهارات }} & \multirow[t]{2}{*}{5} \\
\hline & & غير متوفرة & متوفيرة & محايد & $\begin{array}{l}\text { متوفرة } \\
\text { (4) }\end{array}$ & متوفرة بشدة & & & \\
\hline \multirow[t]{2}{*}{0.851} & \multirow[t]{2}{*}{2.19} & 7 & 29 & 7 & 3 & 1 & s & \multirow[t]{2}{*}{ التعامل باللغات الاجنبية } & \multirow[t]{2}{*}{1} \\
\hline & & 14.9 & 61.7 & 14.9 & 6.4 & 2.1 & $\%$ & & \\
\hline \multirow[t]{2}{*}{0.770} & \multirow[t]{2}{*}{2.19} & 7 & 27 & 10 & 3 & 0 & s) & \multirow{2}{*}{ الرداد وكتابة التقارير والمكاتبات } & \multirow[t]{2}{*}{2} \\
\hline & & 14.9 & 57.4 & 21.3 & 6.4 & 0.0 & $\%$ & & \\
\hline \multirow[t]{2}{*}{1.006} & \multirow[t]{2}{*}{2.34} & 7 & 26 & 7 & 5 & 2 & s] & \multirow{2}{*}{ العمل. } & \multirow[t]{2}{*}{3} \\
\hline & & 14.9 & 55.3 & 14.9 & 10.6 & 4.3 & $\%$ & & \\
\hline \multirow[t]{2}{*}{0.871} & \multirow[t]{2}{*}{2.26} & 7 & 27 & 7 & 6 & 0 & s] & \multirow{2}{*}{ 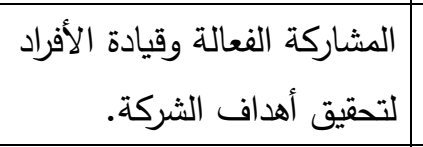 } & \multirow[t]{2}{*}{4} \\
\hline & & 14.9 & 57.4 & 14.9 & 12.8 & 0.0 & $\%$ & & \\
\hline \multirow[t]{2}{*}{0.987} & \multirow[t]{2}{*}{2.36} & 7 & 25 & 7 & 7 & 1 & s] & \multirow{2}{*}{ الملائمة في مجام التقنيات الحديثة. } & \multirow[t]{2}{*}{5} \\
\hline & & 14.9 & 53.2 & 14.9 & 14.9 & 2.1 & $\%$ & & \\
\hline \multirow[t]{2}{*}{0.987} & \multirow[t]{2}{*}{2.36} & 7 & 25 & 7 & 7 & 1 & ك & \multirow{2}{*}{ مالعروضة مهارات الاتصال } & \multirow[t]{2}{*}{6} \\
\hline & & 14.9 & 53.2 & 14.9 & 14.9 & 2.1 & $\%$ & & \\
\hline \multirow[t]{2}{*}{0.987} & \multirow[t]{2}{*}{2.36} & 7 & 25 & 7 & 7 & 1 & ك & \multirow[t]{2}{*}{ التفاعل والعمل مع الفريق } & \multirow[t]{2}{*}{7} \\
\hline & & 14.9 & 53.2 & 14.9 & 14.9 & 2.1 & $\%$ & & \\
\hline 0.954 & 2.30 & 7 & 27 & 6 & 6 & 1 & s & التعامل مع المشكلات في & 8 \\
\hline & & 14.9 & 57.4 & 12.8 & 12.8 & 2.1 & $\%$ & بيئة العمل. & \\
\hline 0.935 & 2.32 & 7 & 25 & 9 & 5 & 1 & 5 & إنجاز المهام المكلف بها في & 9 \\
\hline & & 14.9 & 53.2 & 19.1 & 10.6 & 2.1 & $\%$ & الإطار الزمنى المحدد. & \\
\hline 0.958 & 2.32 & 7 & 26 & 7 & 6 & 1 & s & التعلم الذاتي. & 10 \\
\hline & & 14.9 & 55.3 & 14.9 & 12.8 & 2.1 & $\%$ & & \\
\hline 0.87 & 2.30 & & & مامة & 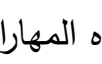 & راسة & & مدوسط & \\
\hline
\end{tabular}


يتضح من الجدول (10) أنه جاء في المرتبة الأولى كلا من مهارة استخدام التقنيات الحديثة الملائمة في مجال العمل، وممارسة مهارات الاتصال والعروض، والتفاعل والعمل مع الفريق بمتوسط حسابي(2.36) في اتجاه عدم توافر المهارة، وجاء في المرتبة الثانية مهارة تتظيم الوقت وتحمل ضغوط العمل بمتوسط حسابي (2.34) في اتجاه عدم توافر المهارة، في حين اشترك كلا من إنجاز المهام المكلف بها في الإطار الزمنى المحدد، والتعلم الذاتي في المرتبة الثالثة بمتوسط حسابي(2.32) في اتجاه عدم توافر المهارة، أما مهارة التعامل مع المشكلات في بيئة العمل فقد جاءت في المرتبة الرابعة بمتوسط حسابي (2.30) في اتجاه عدم توافر المهارة، أما مهارة المشاركة الفعالة وقيادة الأفراد لتحقيق أهداف المؤسسة التي يعمل بها فقد جاءت في المرتبة الخامسة بمتوسط حسابي (2.26) في اتجاه عدم توافر المهارة. في حين اشتركت كلا من مهارة التعامل باللغات الاجنبية، ومهارة إعداد وكتابة التقارير والمكاتبات الرسمية المرتبطة بصناعة السياحة في المرتبة السادسة بمتوسط حسابي (2.19) في اتجاه عدم توافر المهارة، وقد جاء متوسط استجابات عينة الدراسة تجاه محور المهارات العامة بمتوسط حسابي (2.30) في اتجاه عدم توافر المهارة.

\section{نتائج الاراسة الميدانية}

1. تبين عدم وجود علاقة ارتباطية بين مستوى إلمام خريجي قسم الخدمات السياحية بالمدارس الثانوية الفنية السياحية المتقدمة بالمهارات المعرفية ومتطلبات سوق العمل السياحي، حيث جاءت استجابات عينة الدراسة

$$
\text { ضعيفة بمتوسط حسابي } 2.33 .
$$

2. تبين عدم وجود علاقة ارتباطية بين مستوى إلمام خريجي قسم الخدمات السياحية بالمدارس الثانوية الفنية

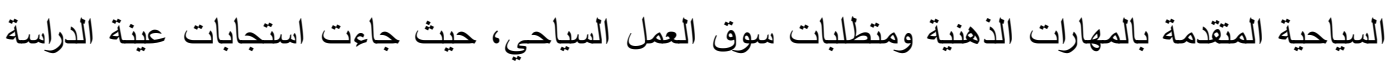
ضعيفة بمتوسط حسابي 2.25.

3. تبين عدم وجود علاقة ارتباطية بين مستوى إلمام خريجي قسم الخدمات السياحية بالمدارس الثانوية الفنية السياحية المتقدمة بالمهارات العملية، ومتطلبات سوق العمل السياحي، حيث جاءت استجابات عينة الدراسة ضعيفة بمتوسط حسابي 2.28. 4. تبين عدم وجود علاقة ارتباطية بين مستوى إلمام خريجي قسم الخدمات السياحية بالمدارس الثانوية الفنية السياحية المتقدمة بالمهارات العامة ومتطلبات سوق العمل السياحي، حيث جاءت استجابات عينة الدراسة ضعيفة بمتوسط حسابي 2.30. النتائج العامة

1- في عام 1989 تم إنشاء المدرسة الفنية المتقدمة للشئون الفندقية والخدمات السياحية نظام السنوات الخمس.

2- تستتد فلسفة التعليم الفني السياحي على إعداد القوى البشرية، وتزويد الطلاب بقدر من الثقافتين العامة المتخصصة، وتوفير العمالة الماهرة، وإتقان أعمال السكرتارية. 
3- تتمثل أبعاد جودة التعليم السياحي الفني المتقدم في بناء العقل المفكر والمنتج، وصناعة أو إنتاج

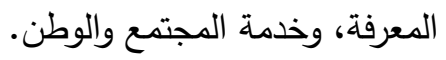

4- تثير نتائج الدراسة الميدانية إلى أن توجهات مديري شركات السياحة بوجه عام نحو" تقييم مستوى

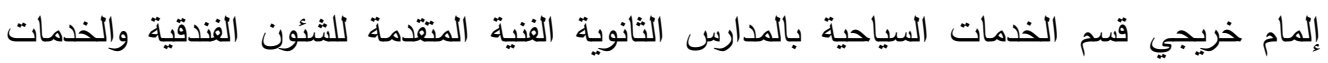

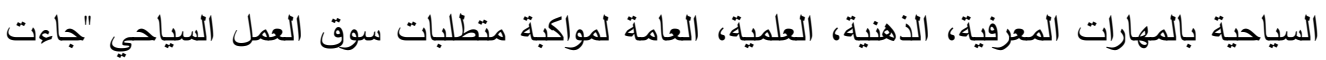

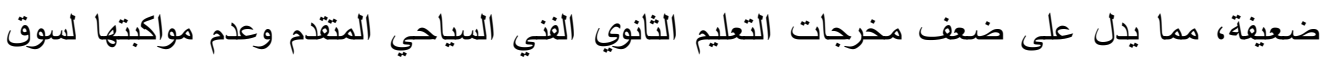
العمل السياحي.

\section{التوصيات}

1- الاهتمام بنشر ثقافة الجودة بين المعلمين داخل المدار الثانوية الفنية المتقدمة للشئون الفندقية والخدمات

$$
\text { السياحية. }
$$

2- التأكد من توصيف البرامج والمقررات ومطابتتها للنتائج التعليمية الدستهذفة. 3- تنفيذ ومراجعة الاستراتيجيات التعليمية واستخدام الوسائل التعليمية المنصوص عليها في وثيقة توصيف

$$
\text { البرنامج التعليمي والمقرر الدراسي الاستراتي }
$$

$$
\text { 4- توفير مصادر التعلم الذاتي للطلاب (الكتب والدوريات، معامل الحاسب الآلي وشبكات الانترنت ....إلخ). }
$$

5- إتاحة إمكانية إنثاء شركات سياحة وفنادق تعليمية تابعة للدارس الثانوية الفنية المتقدمة للشئون الفندقية

$$
\text { والخدمات السياحية لتدريب الطلاب أثناء الدراسة. }
$$

\section{المراجع العربية}

- - الجبوري، ميسر ابراهيم أحمد (2012): التوافق مع معايير اتحاد الجامعات العربية أداة لتعزيز تنافسية قطاع التعليم العالي الخاص، الرياض - المملكة العربية السعودية. - حجي، أحمد اسماعيل (1996): التعليم في مصر ماضيه وحاضره ومستقبله، مكتبة النهضة المصلية المرية،

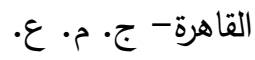

- الحريري، رافدة عمر (2010): القيادة وإدارة الجودة في التعليم العالي، دار الثقافة للنشر والتوزيع، عمان الأردن. - - دريب، محمد جبر (2012): التطبيقات الإجرائية لضمان الجودة في التعليم الجامعي، كلية التربية للبنات،

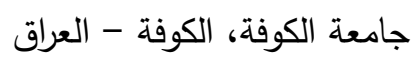

- السامرائي، برهان الدين حسين (2012): دور القيادة في تطبيق أسس ومبادئ إدارة الجودة الثاملة، رسالة ماجستير غير منشورة، الأكاديمية العربية البريطانية للتعليم العالي، الرياض- المعلكة العربية 
- - الثمراني، حامد محمد على (2009): معايير مقترحة للجودة التعليمية في ضوء بالدريج للجودة الثاملة

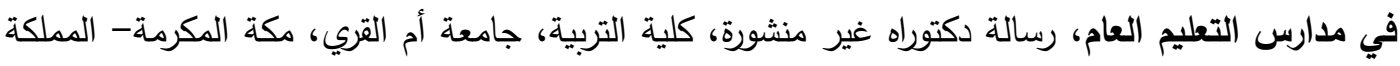
العربية السعودية.

- - الصرايرة، خالد أحمد (2009): ادارة الجودة الثاملة في مؤسسات التعليم العالي، بترا للمؤتمرات، ورقة عمل في المؤتمر التدريبي "ملامح وآفاق الجودة الثاملة في التعليم العالي، عمان - الأردان.

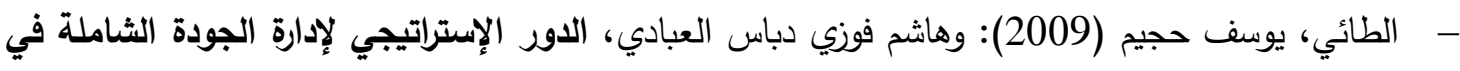
إدارة علاقات الزبون، مجلة العلوم الإنسانية، السنة الخامسة، عمان - الأردن الإن. - عبد الكريم، أحمد عزت (1938): تاريخ التعليم في مصر عهلة محلة محد على، مكتبة النهضة الدصرية،

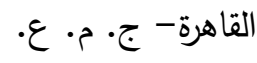

- فؤاد، بسيوني متولي (1989): مجمل تاريخ التعليم العام والفني، دار المعرفة الجامعية للنشر، الاسكندرية-

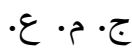
- هويدي، محمود (2006): العلاقة بين التعليم العالي والتدريب والبحث وصناعة السياحة والفنادق، دار

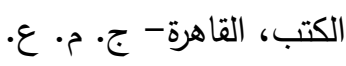

- ـ وزارة التربية والتعليم (1977): وكالة الوزارة للتعليم الفني، تقرير عن التعليم الفني في مصر ، القاهرة- ج. •

- مزارة التربية والتعليم (1978): قرار بثأن تحويل المدرسة الثانوية التجارية بالأقصر الى مدرسة فندقية

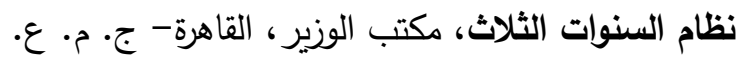

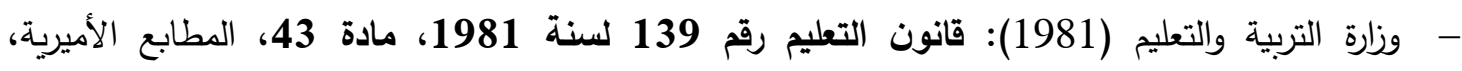

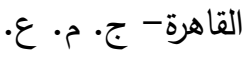

- - وزارة التربية والتعليم (1989): قرار وزاري رقم 192 لسنة 1989 بثأن إنثاء المدرسة الفنية المتقدمة

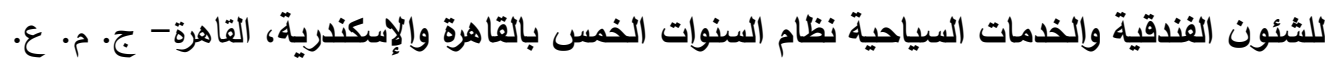

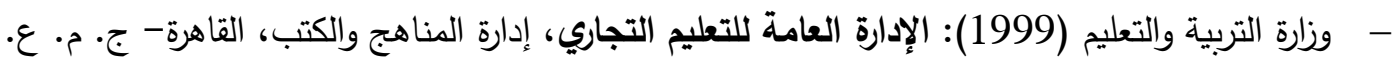

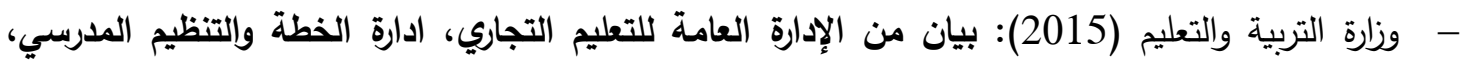
المطابع الأميرية، القاهرة- ج• م. ع. ع. ع. (2015 : بيان عن

المراجع الاجنبية

- Chang, C. T. (2009): Enhancing graduates' employability skills \& competencies for hospitality \& tourism program through Thai qualifications framework and credit transfer. Paper presented at ASAIHL 23rd. Conference, Chiangmai

- Jameson, S. (2008): A case study of international hospitality student's development of employability skills. Gold Coast: Council for Australian Universities Tourism and Hospitality Education Research Information Exchange 
- Kim, J.H. (2008): Career Expectations and Requirements of Undergraduate Hospitality Students and the Hospitality Industry: An Analysis of Differences (Master's thesis). AUT University, Auckland, New Zealand

- Ogbeide, G.C. (2006): Employability skills and students' self-perceived competence for careers in the hospitality industry (Doctoral dissertation). University of Missouri-Columbia, Missouri

- Rees, C., Forbes, P., and Kubler, B. (2006): Student Employability profiles: A guide for higher education practitioners. York The Higher Education Academy

Journal of Association of Arab Universities
for Tourism and Hospitality (JAAUTH)
Vol. 21 No. 1, (December 2021), pp. 195-210.
journal homepage: http://jaauth.journals.ekb.eg

\title{
Evaluating The Quality of Graduates of Advanced Technical Tourism Secondary Education and Its Relationship to the Requirements of work in Tourism Companies in the Delta Region
}

\author{
Ashraf Mohammed Abdelhamid Elsafory
}

Faculty of Tourism and Hotel, Mansoura University

Walid Sayed Amin

Professor of Tourism Studies

Former Dean of the

Faculty of Tourism and Hotels

Mansoura University

\section{Tharwat Ali El Deeb}

Professor of Sociology, Faculty of Arts

Former Vice Dean of the Faculty of Tourism and Hotels for Community Service and Environmental Development, Mansoura University

\section{ARTICLE INFO ABSTRACT}

Keywords:

Quality Assessment;

Tourism Technical

Education, Tourism

Companies in the

Delta Region

\section{(JAAUTH)}

Vol. 21, No. 1, (2021),

PP.195-210.
Tourism education contributes to the development of the tourism industry, by providing human resources capable of meeting the requirements of that industry, and the research aimed to assess the ability and competence of graduates of advanced technical high schools for hotel affairs and tourism services in the Delta region to work in the tourism industry by submitting proposals to develop outputs Technical technical education in tourism and hotels, and the research was based on the descriptive and analytical approach, and the questionnaire was used as a tool to collect the study data, through a random sample of tourism companies managers in the delta region, using the program (SPSS, V. 24) to analyze the data. The research reached many results and recommendations. 